\title{
BMJ Open Attitudes and perceptions of health professionals towards management of hypothyroidism in general practice: a qualitative interview study
}

\author{
Rosie Dew, ${ }^{1}$ Kathryn King, ${ }^{1}$ Onyebuchi E Okosieme, ${ }^{2}$ Simon H Pearce, ${ }^{3}$ \\ Gemma Donovan, ${ }^{1}$ Peter N Taylor, ${ }^{4}$ Janis Hickey, ${ }^{5}$ Colin M Dayan, ${ }^{4}$ Graham Leese, ${ }^{6}$ \\ Salman Razvi, ${ }^{3,7}$ Scott Wilkes ${ }^{1}$
}

To cite: Dew R, King K, Okosieme OE, et al. Attitudes and perceptions of health professionals towards management of hypothyroidism in general practice: a qualitative interview study. BMJ Open 2018;8:e019970. doi:10.1136/ bmjopen-2017-019970

- Prepublication history for this paper is available online. To view these files, please visit the journal online (http://dx.doi org/10.1136/bmjopen-2017019970).

Received 5 0ctober 2017 Revised 12 December 2017 Accepted 16 January 2018

Check for updates

${ }^{1}$ Faculty of Health Sciences and Wellbeing, University of Sunderland, Sunderland, UK ${ }^{2}$ Endocrinology and Diabetes Department, Prince Charles Hospital, Cardiff, UK

${ }^{3}$ Institute of Genetic Medicine, Newcastle University, Newcastle upon Tyne, UK

${ }^{4}$ Institute of Molecular Medicine, School of Medicine, Cardiff University, Cardiff, UK

${ }^{5}$ British Thyroid Foundation, Harrogate, UK

${ }^{6}$ School of Medicine, University of Dundee, Dundee, UK

${ }^{7}$ Department of Endocrinology, Queen Elizabeth Hospital, Gateshead, UK

Correspondence to

Professor Scott Wilkes;

scott.wilkes@sunderland.ac.uk

\section{ABSTRACT}

Objective To explore the attitudes and perceptions of health professionals towards management of hypothyroidism that contributes to the suboptimal treatment of hypothyroidism in general practice.

Design A qualitative interview study using semistructured interviews.

Participants Sixteen participants were interviewed between March and August 2016 comprising nine general practitioners (GPS), four pharmacists, two practice nurses and one nurse practitioner.

Setting General practice and community pharmacies in the counties of Northumberland, Tyne and Wear, Stocktonon-Tees and North Cumbria, North of England, UK.

Method A grounded-theory approach was used to generate themes from interviews, which were underpinned by the theory of planned behaviour to give explanation to the data.

Results Although health professionals felt that hypothyroidism was easy to manage, GPs and nurses generally revealed inadequate knowledge of medication interactions and levothyroxine pharmacokinetics. Pharmacists felt limited in the advice that they provide to patients due to lack of access to patient records. Most GPs and nurses followed local guidelines, and relied on blood tests over clinical symptoms to adjust levothyroxine dose. The information exchanged between professional and patient was usually restricted by time and often centred on symptoms rather than patient education. Health professionals felt that incorrect levothyroxine adherence was the main reason behind suboptimal treatment, although other factors such as comorbidity and concomitant medication were mentioned. Enablers perceived by health professionals to improve the management of hypothyroidism included continuity of care, blood test reminders, system alerts for interfering medications and prescription renewal, and accessible blood tests and levothyroxine prescriptions for patients. Conclusion There is a significant health professional behavioural component to the management of hypothyroidism. Addressing the differences in patient and professional knowledge and perceptions could reduce the barriers to optimal treatment, while continuity of care and increased involvement of pharmacists and practice nurses would help to promote optimal thyroid replacement.
Strengths and limitations of this study

- Suboptimal treatment of hypothyroidism in general practice is common, and behavioural approaches to treatment by health professionals involved in the management of patients with hypothyroidism warrant exploring.

- Confidential discussions with health professionals in this study allowed for rich data of experiences, personal thoughts and perceptions of the management of hypothyroidism to be collected.

- A known potential limitation of qualitative research is the influence the researchers may have had in the process of data gathering and analysis, causing bias. However, to help reduce this limitation, the researcher who conducted the interviews did not have medical training, had not met the participants prior to the interviews or discussed the research with them.

- The small sample size of participants from the North of England may reduce the transferability of the findings of this study to other contexts.

\section{INTRODUCTION}

Hypothyroidism is a common chronic disease caused by insufficient thyroid hormone production. ${ }^{1-3}$ Levothyroxine, a synthetic isomer of the thyroid hormone thyroxine, is used to treat hypothyroidism and is dispensed to $99.7 \%$ of patients with hypothyroidism in England. ${ }^{4}$ Dose increments are made following initiation of treatment to return serum thyroid-stimulating hormone (TSH) levels into the reference range ${ }^{5}$ and provide symptomatic relief. ${ }^{6}$ Without correction, patients with abnormal thyroid results may have an increased risk of cardiovascular disease, dysrhythmias and fractures, ${ }^{7}$ and are at risk of adverse effects on bone mass, ${ }^{8}$ lipid metabolism, ${ }^{9}$ blood pressure ${ }^{10}$ and cognitive function. ${ }^{11} 12$ Even variation in thyroid function within the normal population 
reference range may also be associated with important differences in key health outcomes. ${ }^{13} 14$ Furthermore, neglected hypothyroidism can result in life-threatening myxoedema coma. ${ }^{15}$ Patients with overt hypothyroidism may experience low energy levels, cold intolerance, aches and pains, weight gain and changes in physical appearance.

The management of hypothyroidism is generally carried out in primary care and up until 2014, general practitioners (GPs) were required to maintain a register of patients with hypothyroidism as part of the Quality and Outcomes Framework (QOF). Hypothyroidism is considered a simple condition to manage ${ }^{16}$ and levothyroxine is well tolerated by the majority of patients. ${ }^{17}$ However, the therapeutic benefits of levothyroxine are sometimes unsatisfactory, and TSH levels higher than the reference range have been found in $11 \%-27 \%$ of patients receiving thyroid replacement therapy, while the prevalence of low TSH levels has been reported to range from $20 \%$ to $41 \% .^{718-21}$

Compliance, ${ }^{22} 23$ pharmacogenomics associations ${ }^{24-28}$ and interference from medication and comorbidities, such as autoimmune gastritis and coeliac disease, ${ }^{23}$ have all been found to have an effect on thyroid therapy and it is likely that there are multifactorial reasons for suboptimal treatment. However, only a limited number of studies to date have addressed potential solutions to suboptimal thyroid hormone replacement in general practice. To address this problem, we previously explored the attitudes and perceptions of patients with hypothyroidism towards their treatment. ${ }^{29}$ In the present study, we have investigated the attitudes and perceptions towards the management of hypothyroidism among health professionals including GPs, nurse practitioners (NPs), pharmacists and practice nurses. We sought to determine the clinical management and behavioural factors that may influence the adequacy of thyroid hormone replacement in patients with hypothyroidism.

\section{METHOD}

\section{Design}

Using a grounded theory approach,$^{30}$ qualitative interviews were performed with health professionals to explore their experiences, attitudes and perceptions of the treatment of hypothyroidism. Interviews were conducted by the same researcher (RD) and an initial semistructured topic guide was used (box 1). Themes from initial interviews were explored and developed in subsequent interviews, and were mapped to the constructs of the Theory of Planned Behaviour (TPB) to give an overall explanation of the data. The TPB describes the association between an individual's beliefs and their behaviour by considering the influence of their attitude towards a particular behaviour, subjective norms and perceived behavioural control. ${ }^{31}$

\section{Box 1 Initial topic guide for interviews}

What is your role in the management of patients with hypothyroidism? Symptoms of hypothyroidism

- How would you describe your familiarity with the symptoms of hypothyroidism?

- Are you confident to spot patients with hypothyroidism? Why? Example?

-What makes you suspect hypothyroidism? Why? Example?

Diagnosis

- How would you describe your confidence in making a diagnosis of hypothyroidism?

Referral

D Do you refer patients who have abnormal thyroid function tests? Can you describe the process?

Do you refer patients to get a diagnosis of hypothyroidism?

Who do you refer to? Can you describe the process?

Management

- What do you think about the management of hypothyroidism in general practice? Are you happy to manage hypothyroidism in general practice?

How often do you check thyroid function tests?

Does this differ for controlled/out of control patients?

- Are there any instances when you would refer/seek help? Example?

- How do you manage patients who complain of symptoms and the thyroid-stimulating hormone (TSH) are in the normal range? Example? Or would in theory? What are your thoughts on this?

Do you find it difficult to keep the TSH in the reference range?

-What do you think about changing levothyroxine dose for patients? Do you think the increments of $25 \mu \mathrm{g}$ of levothyroxine too great?

- What are your thoughts about patients with hypothyroidism who are out of control? Are you concerned about patients with hypothyroidism who are out of control?

- What are your thoughts on patients with: - High TSH (usually indicating too little levothyroxine)? - Low TSH (usually indicating too much levothyroxine)?

- How do you manage patients who insist on taking more levothyroxine than their TSH suggests (ie, oversuppressed)?

- What do you think about patients who have high TSH blood tests which suggests that they are not taking enough levothyroxine? Have you experienced this?

- What are the main influences that you see that contribute to patients struggling to control their hypothyroidism?

- Can you predict which patients will struggle to control their hypothyroidism? Example?

\section{Setting}

Health professionals from general practice and community pharmacies in the counties Northumberland, Tyne and Wear, Stockton-on-Tees and North Cumbria, North of England, were invited to take part. Interviews were conducted between March and August 2016.

\section{Participants}

Sixteen one-off interviews were conducted with nine GPs, four pharmacists $(\mathrm{P})$, two practice nurses $(\mathrm{N})$ and one NP. Participants were recruited through the NIHR Clinical Research Network: North East and North Cumbria and local professional networks via mail and email, and participants were given the option to contact the researcher if 
they wanted to take part. Most interviews were conducted face to face at the participant's place of work or the University of Sunderland. However, due to participant availability, one GP was interviewed at home, and one GP was interviewed by telephone. Only the participant and the researcher were present during the interviews, and the researcher had not met the participants previously. Most participants were not known to each other; however, three pharmacists had lecturing roles at the University of Sunderland and were known to each other.

Confidentiality was assured, the process of the research explained and written consent was obtained prior to the interview. Interviews lasted approximately $45 \mathrm{~min}$ and interviewees were not paid for participation.

\section{Sampling}

Using purposive sampling, participants were recruited from both rural and urban areas to provide an initial maximum variation sample. ${ }^{30}$ To test emerging themes, theoretical sampling thereafter proceeded until data saturation was achieved and no new themes were forthcoming $^{32}$ in the following two interviews. Data gathered from the interview with the NP was similar to that of the data obtained from the interviews with the practice nurses. Data saturation occurred quickly in the information provided by the interviews from our allied health professional group; thus, more GPs were recruited than other health professionals.

\section{Analysis}

Interviews were audio recorded and transcribed verbatim, and analysis was performed using Microsoft Word 2010. Open coding of transcripts preceded the categorisation of the data, and as the interviews progressed, themes emerging from the data were tested in subsequent interviews. ${ }^{33}$ Notes made by RD after the interviews were considering during analysis. Data analysis occurred concurrently with the interviews, and constant comparison and iterative analysis of the interview data allowed for development and remodelling of themes until data saturation was achieved. ${ }^{30}$ Coding was performed by RD and in-depth data analysis and negotiation of themes were conducted by RD, KK and SW. Transcripts were returned to participants for comments and corrections; however, no feedback was received.

\section{RESULTS}

Participant characteristics are shown in table 1. Participant age ranged from 25 to 60 years, and 4 participants were men and 12 were women, with 6 participants working in rural areas and 10 working in urban areas. The three main themes that emerged from the data were perceived health professional control, perceived health professional responsibility and attitudes to thyroid control, which were underpinned to the TPB as shown in figure 1.

\begin{tabular}{|c|c|c|c|c|}
\hline Job role & Location & Age & Gender & Years qualified \\
\hline \multicolumn{5}{|c|}{ General practitioner (GP) } \\
\hline GP-1 & Urban & 45 & Female & 10 \\
\hline GP-2 & Rural & 40 & Male & 14 \\
\hline GP-3 & Urban & 59 & Female & 36 \\
\hline GP-4 & Urban & 36 & Female & 10 \\
\hline GP-5 & Urban & 39 & Female & 16 \\
\hline GP-6 & Urban & 51 & Male & 27 \\
\hline GP-7 & Rural & 52 & Female & 29 \\
\hline GP-8 & Rural & 39 & Female & 14 \\
\hline GP-9 & Rural & 48 & Male & 20 \\
\hline \multicolumn{5}{|c|}{ Nurse practitioner (NP) } \\
\hline NP-1 & Rural & 55 & Female & 35 \\
\hline \multicolumn{5}{|c|}{ Practice nurse $(\mathrm{N})$} \\
\hline $\mathrm{N}-1$ & Urban & 58 & Female & 40 \\
\hline $\mathrm{N}-2$ & Rural & 60 & Female & 40 \\
\hline \multicolumn{5}{|c|}{ Community pharmacist $(\mathrm{P})$} \\
\hline$P-1$ & Urban & 30 & Male & 8 \\
\hline $\mathrm{P}-2$ & Urban & 29 & Female & 6 \\
\hline P-3 & Urban & 39 & Female & 15 \\
\hline$P-4$ & Urban & 25 & Female & 2 \\
\hline
\end{tabular}

\section{Perceived health professional control}

\section{Management of hypothyroidism}

Generally health professionals found the management of hypothyroidism straightforward, relying on blood tests over non-specific clinical symptoms. However, there was uncertainty whether to start levothyroxine treatment in asymptomatic patients with borderline TSH levels, or patients with suggestive hypothyroid symptoms that did not have elevated TSH levels:

It's relatively commonly and easily managed. And the medication is generally quite palatable for patients. And they largely feel better. (GP-1)

I think it's something that we often go into a bit of autopilot because we rely more on blood tests. (GP-6)

Should you treat them or should you not? ...we'll just keep an eye on the blood test. The other side of the coin is that they get labelled and start having treatment for something when actually if you just left them alone they would have been fine. (GP-8)

Some health professionals recounted patients finding information on levothyroxine alternatives from online forums. Alternative treatments or referring to an endocrinologist was a last resort following the unsuccessful management of TSH with levothyroxine. Only a minority described alternatives including liothyronine (a synthetic form of triiodothyronine, T3), armour thyroid (desiccated porcine thyroid extract) and homeopathic alternatives. Health professionals had a tentative approach 


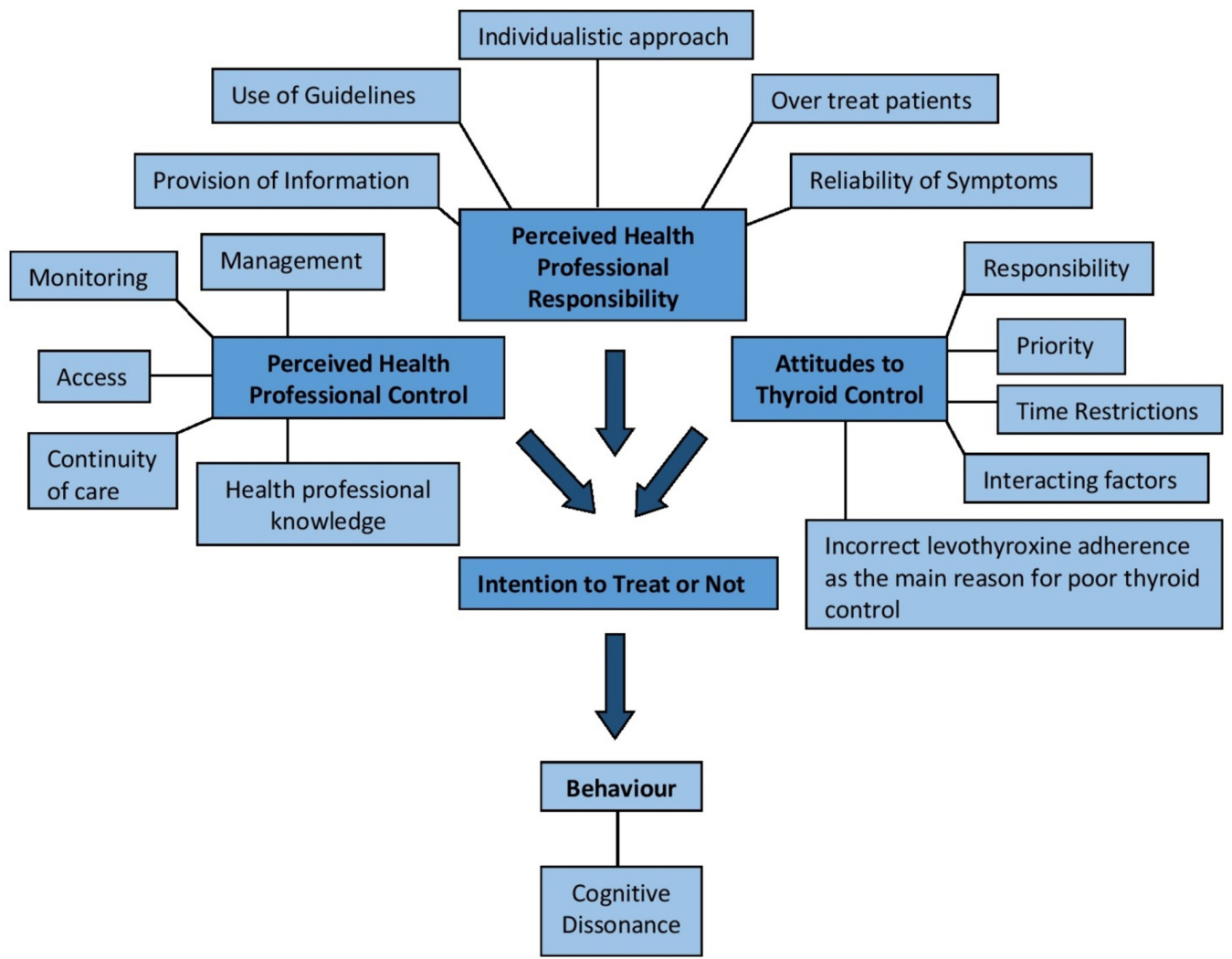

Figure 1 Concept diagram showing the attitudes and perceptions of health professionals towards the management of hypothyroidism in general practice.

to levothyroxine alternatives, even with one example of a patient reporting feeling much better taking liothyronine, despite TSH and T3 levels suggesting overtreatment:

People research it and they'll come back and say, 'I want the T3 because it's better.' (GP-2)

She is taking liothyronine... she had never felt better. But her TSH and her T3... suggest she's being overtreated. (NP)

\section{Monitoring of hypothyroidism}

Health professionals felt that blood test reminders and prescription renewal alerts were enablers of good thyroid management as were alerts to potentially interacting medication:

One of our admin team does a regular search and just finds out who's out of date with their blood tests. (GP-7)

Because it's so good now, the computer system... Because it also alerts you if the doctors are prescribing something that interacts $(\mathrm{N}-2)$

\section{Access}

Easy access to blood tests and electronic prescriptions were perceived by GPs to help patients access their levothyroxine; however, concern was raised that patients in nursing homes might not be as tightly monitored:

Electronic prescriptions and things have been helpful... not having the money, I guess, to get the bus up to pick up a prescription... we can send prescriptions electronically to the chemist. (GP-4)

We do have phlebotomy appointments in the evenings and weekends. (GP-7)

\section{Continuity of care}

Continuity of care was perceived by GPs to be important for the management of patients with hypothyroidism. Interpretation of normal thyroid function was difficult without matching patients' expectations, symptoms and blood tests results:

So continuity of care does make a difference to patients who are difficult to manage or where compliance is potentially a problem. Because if they start dotting all over the place, then you know you have to work that thread back up. And it's all about trust. A lot of it is about trust in the GP. And that comes from continuity of care. (GP-1)

I think sometimes if blood test results are going back to a different [GP] than normally sees the patient, then it may just say 'normal'. And there's a risk that you would just say normal. (GP-7)

Pharmacists felt the advice they could give patients was limited by their lack of access to patient medical records, and that they could only advise depending on a patient's account of their TSH results and medications. Pharmacists felt that access to TSH results would save time and inaccuracies in advice they give: 
And that's something that, you know, it would really help us if we had access to things like TSH results and things. Just as a second check, I think. (P-2)

\section{Health professional knowledge}

GPs and nurses felt they would need to check which medications may interact with levothyroxine, and it was generally perceived that their knowledge of hypothyroidism pharmacokinetics could be increased. Most health professionals felt that the GP had overall responsibility for knowledge acquisition:

I mean, off the top of my head, I actually couldn't tell you any interactions between thyroxine... Apart from... I think it's iron. (GP-8)

I suppose I haven't really taken the trouble to learn because I know that somebody else is doing it. (N-2)

GPs and pharmacists generally perceived that patient knowledge of thyroid function was basic. Pharmacists mostly felt that patients were unaware of the risk of undertreatment or overtreatment with levothyroxine:

I don't think many of them can really tell you what it's for, what the thyroid does or what the risks are of going too high or too low. (P-1)

\section{Perceived health professional responsibility \\ Provision of information}

Generally health professionals provided verbal information about hypothyroidism and the importance of blood tests. Pharmacists described the need to avoid multivitamins, iron containing drugs, calcium containing drugs, indigestion remedies and coffee. Health professionals generally did not explain the effects of hypothyroidism on the thyroid:

I'm not a leaflet person. I like to talk and tell them. And if I've got a visual aid, using the computer. I'll explain to that. (NP-1)

Best in the morning. Not to take it [levothyroxine] with anything else-certainly not a cup of coffee. (P-3)

Generally, health professionals perceived that patients researched their own condition, or they would use leaflets from, or direct patients to patient.co.uk:

These days I would generally tell people to look it up on the internet. And I would usually direct them to a website. These days, mainly patient.co.uk. (GP-9)

You know, they're quite happy, and they'll often do research themselves. (GP-1)

\section{Use of guidelines}

Local guidelines were used by the majority of GPs, although many were reliant on the laboratory reference ranges. A few GPs felt that their management of hypothyroidism was not based on any guidelines:
I think that's all in the TRAMP [Thyroid Regional Assessment and Management Plan, NHS North of Tyne and Gateshead Area Prescribing Committee, North of England] guidelines. I think I try to follow what I'm meant to do. (GP-4)

I think the idea is just to try and get the result sitting somewhere in that [laboratory reference range]. (GP-8)

You interpret the guidelines to treat the patient, not fitting the patient to the guideline. (GP-3)

\section{Individualistic approach}

Most GPs and nurses perceived that an individualistic approach was necessary for optimal thyroid hormone replacement for each patient. The general consensus was that GPs were happy to increase levothyroxine doses to make patients feel better as long as TSH levels remained within range:

I aim to get them within range and feeling okay. (GP-9)

I know there is evidence to suggest that you should keep them more to the suppressed end. If they're in the parameters, to me, they are controlled. (NP-1)

\section{Overtreatment with levothyroxine}

Health professionals described the difficulty of attributing symptoms to thyroid disease when a levothyroxine-treated patient's TSH remains in range:

But my instinct is that if you say you're unwell and your thyroid blood tests are normal, I don't think you're unwell because of your thyroid problem. I would be... I would be very reluctant to give somebody extra thyroxine just in case. (GP-6)

GPs and nurses were conscious of the cardiac complications associated with giving a patient too much levothyroxine too quickly. Extra caution was described when treating the elderly where the risks of fractures may be high:

You need to be careful that you don't suppress it too much, because that comes with some clinical risks around fractures-particularly in elderly patients. (GP-1)

Most GPs and the NP were not prepared to overtreat patients with levothyroxine due to the associated risks. One GP recounted that she had intentionally oversuppressed a patient's TSH level, explaining that she knew the patient well; the patient had a good knowledge of their condition, was aware of the risks of oversuppression and was miserable on a lower dose. However, another GP felt that some colleagues choose to ignore over suppression of TSH:

And if that little old lady then falls over or fractures...

And sues you, because you've, you know, artificially suppressed her TSH. (GP-1) 
I felt that she was making an informed decision. She knew what the risks were. Especially as she got older... being over-treated. (GP-3)

I've worked in a new practice, patients that have had TSH below 0.02 for a long time and they've just been told it's normal. (GP-5)

\section{Reliability of hypothyroid symptoms}

Health professionals had a good knowledge of hypothyroid symptoms and felt that if they knew the patient then developing slowness and change in mood made them suspect hypothyroidism. GPs felt that the symptoms of hypothyroidism were non-specific and overlapped with a number of clinical conditions. Moreover, health professionals perceived that patients often feel that their thyroid is accountable for many symptoms, particularly weight gain and tiredness:

So, you know, tiredness being one, weight gain being another, dry skin, intolerance to cold. But... Those are symptoms of lots of conditions, both physical health and mental health problems. (GP-1)

Once they've got a diagnosis of underactive thyroid, I think they blame it. (GP-2)

\section{Attitudes to thyroid control \\ Responsibility}

Health professionals felt that it was the patient's responsibility to attend blood tests, for good medication adherence, and to challenge the GP if they were feeling symptomatic; however, it was perceived that the GP had overall responsibility:

I think it's in partnership. Because if the patient doesn't take the tablets, then you're not going to get control... and you don't check the blood tests and manage them appropriately, you're not going to get good control. (GP-3)

Mainly the GP it's their GP, who's got the overall responsibility of looking after that patient. (NP-1)

\section{Incorrect levothyroxine adherence as the main reason for} suboptimal treatment

Some health professionals in our study felt that avoiding weight gain encouraged levothyroxine adherence in patients. Health professionals believed that poor adherence was the main reason patients struggle to lower TSH levels. Additionally, the majority of health professionals said they had experienced a small proportion of patients who would take more levothyroxine than prescribed to alleviate tiredness or in an attempt to lose weight:

They think, oh, if I don't take it, I'll put even more weight on. So I think there is a lot of that going on. $(\mathrm{N}-2)$

Certainly one patient I can remember who had said he had been feeling tired and have been taking an extra tablet. (P-1)

... likes to run his TSH low. And there is no arguing with him, because he will just take what he wants to take. He'll come in and lie. (GP-8)

\section{The priority of hypothyroidism}

Health professionals believed patients may not prioritise hypothyroidism over health conditions such as heart disease, diabetes, hypertension and hypercholesterolaemia, and hypothyroidism was not a routine focus of medication reviews. Removal of hypothyroidism from the QOF targets led to suspicions of reduced control and monitoring in some practices:

People who are on Dosette trays... they're more concerned about the other conditions that they have. (P-3)

There's certain drugs that we get, sort of, payment for sitting down with patients and really going through how they work and how they should be taken. (P-2)

And it used to be a QOF target that each year they had to have an annual TSH, which was a very easy target to hit. And then it stopped about two years ago. So I think some practices, potentially, have sort of let their thyroid management drop. (GP-2)

\section{Time restrictions}

GPs and pharmacists felt that lack of time limited the information exchanged when speaking to a patient. One pharmacist felt there was pressure to focus on medication reviews, reducing the time available to give advice to other patients:

You're always short of time. It's always a problem. (GP-7)

They encourage us to do new services, such as medication use reviews and new medicine service reviews in pharmacies. We don't necessarily have as much time as we would like to stand on the counter and talk to patients (P-1)

Concern over prioritising the busy GP workload was articulated, with thyroid function tests potentially accepted as being normal when they may not be:

And we've got an awful lot on our plates-using that old excuse again. But we're really, really busy. And... Sometimes the blood results come through and you're just like, well, actually they might have missed it for the last few days or whatever. And just bounce it through, you know. And then the patient... It's on the patient's head to ring up for their results and check that their levels are okay. (GP-8)

\section{Factors that interact with treatment for hypothyroidism}

GPs and pharmacists felt that if patients had an elevated TSH but reported that they were compliant then it may be due to other medication affecting the absorption of levothyroxine. Health professionals also felt that stress, diet, alcohol, coffee, smoking, having a busy lifestyle, comorbidities, other medications, mental health, 
learning disabilities, deafness and dementia could all have an effect on optimal thyroid hormone replacement:

So I guess when it's [TSH] too high it's usually like what I said before-are you taking your medication at all? Are there other reasons why it might be that you're not absorbing it? Like the medication? Other conditions? (GP-4)

And I don't think people had realised for many years, is the caffeine thing. And that's the kind of thing that could come out in an MUR [medicine use review]. So are they drinking it with a cup of coffee in a morning? And calcium supplements as well. (P-3)

\section{DISCUSSION}

\section{Principal findings}

Regarding perceived professional control, health professionals felt that hypothyroidism was an easy condition to manage, and felt they relied on blood tests over non-specific clinical symptoms to confirm a diagnosis. However, health professionals generally perceived they had a lack of in-depth knowledge of medication interaction. On the other hand, pharmacists felt they could provide limited advice due to their lack of access to patient data and lack of time. Enablers perceived by health professionals to improve the management of hypothyroidism included continuity of care, reminders for blood tests, system alerts for medication interactions and prescription renewal, and easy access to blood tests and levothyroxine prescriptions for patients.

In terms of perceived professional responsibility, most GPs and the NP followed local guidelines for the management of hypothyroidism, and would only increase the levothyroxine dose to improve symptom control as long as TSH levels remained within range. However, one GP recounted oversuppressing a patient at the patient's request. The information exchanged between health professional and patient was limited by time restrictions, with most GPs and nurses assuming that patients would research their condition online. Written information leaflets were rarely provided to patients.

Attitudes to thyroid control included perceiving hypothyroidism as less serious and more straightforward than other health conditions and that taking too much or too little levothyroxine was the main reason for inadequate thyroid control. However, interfering factors such as stress, other conditions and concomitant medication were acknowledged. GPs felt they were mainly responsible for a patient's treatment, but stressed that good medication adherence by patients was important for optimal treatment.

Health professionals will usually strive to hold all attitudes, beliefs and behaviours in harmony. ${ }^{34}$ However, this study has highlighted the cognitive dissonance between attitudes and beliefs versus behaviours that exist.

\section{Comparisons with existing literature}

Similar to the findings of our study, the management of hypothyroidism has been reported to be straightforward. ${ }^{16}$ Like the GPs in our study, continuity of care was described by GPs in a previous qualitative study to enable them to provide higher quality of care in general practice due to the personal relationships that had formed. ${ }^{35}$ However, health professionals generally felt they had incomplete knowledge of hypothyroidism, which was also found for other diseases such as gout ${ }^{36}$ and dementia. ${ }^{37}$ Access to patients medical records suggested by the pharmacists in this study has also been recommended to improve care and patient safety within Britain by the Royal Pharmaceutical Society. ${ }^{38}$ Including pharmacists in healthcare teams has been shown to reduce hospital admissions and medical costs of patients aged 80 years of age or older in Sweden, ${ }^{39}$ and pharmacist involvement has also been associated with lower rates of adverse drug events. ${ }^{40}$

Deliberate TSH suppression $(<0.1 \mathrm{mU} / \mathrm{L})$ with high doses of levothyroxine, which was avoided by the majority of GPs in our study, is not recommended due to the potential risk of heart disease, stroke, osteoporosis and fractures. ${ }^{41}$ In our previously published work with patients with hypothyroidism, patients felt that health professionals were more inclined to treat their TSH levels than their symptoms and that they were not given very much information at the time of diagnosis, ${ }^{29}$ as reported by some health professionals in this study.

Time was a barrier to thyroid management identified by health professionals in our study, and is a well-documented limitation in primary care. ${ }^{42}{ }^{43}$ However, previous studies have shown that although time is a limitation in terms of the information exchanged, it is consultation quality rather than the length of appointment that is more impactful. ${ }^{43}$ Poor levothyroxine adherence, medication interactions and comorbidities have been reported to have an effect on thyroid replacement therapy, ${ }^{44}$ which were some of the barriers reported in this study. However, in our qualitative interview study with patients with hypothyroidism, although not generalisable outside of the patient population, good levothyroxine adherence was reported by nearly all patients, even those who had TSH levels outside of the reference range,$^{29}$ suggesting that the reasons for inadequate thyroid treatment may lie deeper than the typical assumptions by health professionals that poor adherence is the main reason for suboptimal treatment. $^{22} 23$

\section{Strengths and weaknesses}

Due to time restrictions of this research project, this study did not have the opportunity to be pilot tested, which may have affected how the interviews progressed. Moreover, no feedback on the transcripts was provided by participants; feedback may have contributed to enriching the data further. Open coding was performed by RD; however, negotiation of categories and themes were conducted by $\mathrm{RD}, \mathrm{KK}$ and SW to help reduce this limitation. 
Since our sample only included four pharmacists and three nurses, the evidence presented from these groups may lack validity and generalisability outside of this small sample size. Moreover, a different sample of participants with different levels of experience may have provided different results, particularly pharmacists with more years of experience, and also from rural areas. Additionally, within our GP sample, it was unknown whether those who took part in our study were more likely to follow guidelines and regularly review patients, thus being less likely to have higher numbers of thyroxine-treated patients with abnormal TSH than those who did not take part in our study. However, although this study was conducted with a sample of 16 participants in the North of England, and may not be generally applicable, the findings are transferrable within this professional population, and this study provides novel insights into the attitudes, experiences and behaviour of health professionals involved in the management of hypothyroidism.

\section{Implications for future research and clinical practice}

To help increase perceived health professional control in the future, quantifying the extent that clinical, behavioural and pharmacogenomic associations may affect levothyroxine therapy and providing this information to health professionals involved in management of hypothyroidism may improve management and therefore treatment for this group of patients. However, it should be considered that health professionals in general practice have limited time and specialism. Moreover, increasing the involvement of pharmacists or practice nurses in the management of hypothyroidism may improve their perceived control and help relieve the pressure on GPs, and may also increase continuity of care, for example, through pharmacist-led medication reviews or specific chronic disease management clinics for this cohort of patients.

To reinforce perceived health professional responsibility, consistent provision of patient information leaflets and discussions about hypothyroidism would help increase patient understanding and this type of information can be exchanged in a short period of time, and may reduce the time pressures on GPs if patients are more informed. Finally, clarity on the timing of initiation of treatment in asymptomatic patients with slightly elevated TSH, and an age specific and symptom focus where appropriate may help to improve the management of patients with hypothyroidism within general practice.

Acknowledgements Thank you to Shona Haining, Claire Graham and Sally Dunn, supported by the NIHR Clinical Research Network: North East and North Cumbria, working for North of England Commissioning Support unit, for their efficient and effective assistance during recruitment of participants. Finally, many thanks to all the health professionals who volunteered to be interviewed in our study.

Contributors SW designed the study. RD was responsible for the recruitment and interviewing of participants, wrote the first draft of this paper and gained qualitative research skills through attendance at a qualitative interview training course at Newcastle University, and from working on previous research projects. RD, SW and KK were involved in the in-depth data analysis and development of themes that emerged from the data. OEO, SP, GD, PNT, JH, CMD, GL and SR were involved in the overall explanation of the data and revision of the final manuscript.
Funding This work was supported by Amdipharm Mercury Company Limited (RT/6702). The authors would like to acknowledge the University of Sunderland for sponsoring this study.

Disclaimer The funder has had no influence on the design, analysis or production of this manuscript. All researchers involved in the production of this paper are independent from the funder.

Competing interests None declared.

Patient consent Not required.

Ethics approval Ethical approval was granted from NRES Committee West Midlands-South Birmingham REC (REC reference 15/WM/0345) with SSA approval from Northumberland, Gateshead, and South Tyneside Local Research Ethics Committees. Approval was also granted from the University of Sunderland Research Ethics Committee.

Provenance and peer review Not commissioned; externally peer reviewed. Data sharing statement № additional data are available.

Open Access This is an Open Access article distributed in accordance with the Creative Commons Attribution Non Commercial (CC BY-NC 4.0) license, which permits others to distribute, remix, adapt, build upon this work non-commercially, and license their derivative works on different terms, provided the original work is properly cited and the use is non-commercial. See: http://creativecommons.org/ licenses/by-nc/4.0/

(c) Article author(s) (or their employer(s) unless otherwise stated in the text of the article) 2018. All rights reserved. No commercial use is permitted unless otherwise expressly granted.

\section{REFERENCES}

1. Tunbridge WM, Evered DC, Hall R, et al. The spectrum of thyroid disease in a community: the Whickham survey. Clin Endocrinol 1977;7:481-93.

2. Vanderpump MPJ. et a/The Epidemiology of Thyroid Diseases. In: Werner SC, Ingbar SH, Braverman LE, Utiger RD, ; Werner \& Ingbar's the thyroid: a fundamental and clinical text. Philadelphia, USA: Lippincott Williams \& Wilkins, 2005;549:398-406.

3. Chaker L, Bianco AC, Jonklaas J, et al. Hypothyroidism. Lancet 2017;390:1550-62.

4. Health and Social Care Information Centre (HSCIC). Prescriptions dispensed in the community England 2005-2015, 2016.

5. Beastall GH, Beckett GJ, Franklyn J, et al; UK guidelines for the use of thyroid function tests: The Association for Clinical Biochemistry, British Thyroid Association, British Thyroid Foundation, 2006.

6. Vanderpump MPJ, Ahlquist JAO, Franklyn JA, et al. Consensus statement for good practice and audit measures in the management of hypothyroidism and hyperthyroidism. BMJ 1996;313:539-44.

7. Flynn RW, Bonellie SR, Jung RT, et al. Serum thyroid-stimulating hormone concentration and morbidity from cardiovascular disease and fractures in patients on long-term thyroxine therapy. J Clin Endocrinol Metab 2010;95:186-93.

8. Uzzan B, Campos J, Cucherat M, et al. Effects on bone mass of long term treatment with thyroid hormones: a meta-analysis. J Clin Endocrinol Metab 2011;81:4278-89.

9. Duntas LH. Thyroid disease and lipids. Thyroid 2002;12:287-93.

10. Fommei $\mathrm{E}$, lervasi $\mathrm{G}$. The role of thyroid hormone in blood pressure homeostasis: evidence from short-term hypothyroidism in humans. $J$ Clin Endocrinol Metab 2002;87:1996-2000.

11. Juárez-Cedillo T, Basurto-Acevedo L, Vega-García S, et al. Prevalence of thyroid dysfunction and its impact on cognition in older mexican adults: (SADEM study). J Endocrinol Invest 2017;40:945-52.

12. McMillan C, Bradley C, Razvi S, et al. Evaluation of new measures of the impact of hypothyroidism on quality of life and symptoms: the ThyDQoL and ThySRQ. Value Health 2008;11:285-94.

13. Dayan CM, Saravanan P, Bayly G. Whose normal thyroid function is better--yours or mine? Lancet 2002;360:353-4.

14. Taylor PN, Razvi S, Pearce SH, et al. Clinical review: A review of the clinical consequences of variation in thyroid function within the reference range. J Clin Endocrinol Metab 2013;98:3562-71.

15. Fliers E, Wiersinga WM. Myxedema coma. Rev Endocr Metab Disord 2003;4:137-41.

16. Vaidya B, Pearce $\mathrm{SH}$. Management of hypothyroidism in adults. BMJ 2008;337:a801.

17. Biondi B, Wartofsky L. Combination treatment with T4 and T3: toward personalized replacement therapy in hypothyroidism? $\mathrm{J}$ Clin Endocrinol Metab 2012;97:2256-71. 
18. Somwaru LL, Arnold AM, Joshi N, et al. High frequency of and factors associated with thyroid hormone over-replacement and under-replacement in men and women aged 65 and over. $J$ Clin Endocrinol Metab 2009;94:1342-5.

19. Okosieme OE, Belludi G, Spittle K, et al. Adequacy of thyroid hormone replacement in a general population. QJM 2011;104:395-401.

20. Parle JV, Franklyn JA, Cross KW, et al. Thyroxine prescription in the community: serum thyroid stimulating hormone level assays as an indicator of undertreatment or overtreatment. $\mathrm{Br} J$ Gen Pract 1993;43:107-9.

21. Taylor PN, lqbal A, Minassian C, et al. Falling threshold for treatment of borderline elevated thyrotropin levels-balancing benefits and risks: evidence from a large community-based study. JAMA Intern Med 2014;174:32-9.

22. Briesacher BA, Andrade SE, Fouayzi $\mathrm{H}$, et al. Comparison of drug adherence rates among patients with seven different medical conditions. Pharmacotherapy 2008:28:437-43.

23. Robertson HM, Narayanaswamy AK, Pereira O, et al. Factors contributing to high levothyroxine doses in primary hypothyroidism: an interventional audit of a large community database. Thyroid 2014;:24:1765-71.

24. Andersen $\mathrm{S}$, Pedersen $\mathrm{KM}$, Bruun $\mathrm{NH}$, et al. Narrow individual variations in serum $\mathrm{T}(4)$ and $\mathrm{T}(3)$ in normal subjects: a clue to the understanding of subclinical thyroid disease. $J$ Clin Endocrinol Metab 2002;87:1068-72.

25. van der Deure WM, Friesema EC, de Jong FJ, et al. Organic anion transporter 1B1: an important factor in hepatic thyroid hormone and estrogen transport and metabolism. Endocrinology 2008;149:4695-701.

26. Torlontano M, Durante C, Torrente I, et al. Type 2 deiodinase polymorphism (threonine 92 alanine) predicts L-thyroxine dose to achieve target thyrotropin levels in thyroidectomized patients. $J$ Clin Endocrinol Metab 2008;93:910-3.

27. Taylor PN, Porcu E, Chew S, et al. Whole-genome sequence-based analysis of thyroid function. Nat Commun 2015;6.

28. Panicker V, Saravanan $\mathrm{P}$, Vaidya B, et al. Common variation in the $\mathrm{DIO} 2$ gene predicts baseline psychological well-being and response to combination thyroxine plus triiodothyronine therapy in hypothyroid patients. J Clin Endocrinol Metab 2009;94:1623-9.

29. Dew R, King K, Okosieme OE, et al. Patients' Attitudes and Perceptions towards Treatment of Hypothyroidism in General Practice. BJGP Open 2017;1:BJGP-2017-0125.
30. Strauss AL, Corbin JM. Basics of qualitative research. Grounded theory proceedures and techniques. London: Sage Publications, 1990.

31. Ajzen I. The theory of planned behavior. Organ Behav Hum Decis Process 1991;50:179-211.

32. Glaser B, Strauss A. The discovery of grounded theory. Chicago: Aldine, 1967.

33. Denzin NK, Lincoln YS. Handbook of qualitative research. London: Sage Publications, 1994.

34. Festinger L. A theory of cognitive dissonance. California: Stanford University Press, 1957.

35. Ridd M, Shaw A, Salisbury C. 'Two sides of the coin' - the value of personal continuity to GPs: a qualitative interview study. Fam Pract 2006;23:461-8

36. Spencer K, Carr A, Doherty M. Patient and provider barriers to effective management of gout in general practice: a qualitative study. Ann Rheum Dis 2012;71:1490-5.

37. Pathak KP, Montgomery A. General practitioners' knowledge, practices, and obstacles in the diagnosis and management of dementia. Aging Ment Health 2015;19:912-20.

38. Royal Pharmaceutical Society England. Shaping pharmacy for the future: Pharmacist access to the patient health record, 2014

39. Gillespie U, Alassaad A, Henrohn D, et al. A comprehensive pharmacist intervention to reduce morbidity in patients 80 years or older: a randomized controlled trial. Arch Intern Med 2009;169:894-900

40. Schnipper JL, Kirwin JL, Cotugno MC, et al. Role of pharmacist counseling in preventing adverse drug events after hospitalization. Arch Intern Med 2006;166:565-71.

41. Okosieme O, Gilbert J, Abraham P, et al. Management of primary hypothyroidism: statement by the British Thyroid Association Executive Committee. Clin Endocrinol 2016;84:799-808.

42. Albers-Heitner P, Berghmans B, Nieman F, et al. Adherence to professional guidelines for patients with urinary incontinence by general practitioners: a cross-sectional study. J Eval Clin Pract 2008;14:807-11.

43. Dugdale DC, Epstein R, Pantilat SZ. Time and the patientphysician relationship. J Gen Intern Med 1999;14 (Suppl 1):S34-S40.

44. Okosieme OE. Thyroid hormone replacement: current status and challenges. Expert Opin Pharmacother 2011;12:2315-28. 